\title{
Effect of Mental Illness on the Primary Care Givers: A Case Study of Mathari Hospital, Kenya
}

\author{
Rogers S Songole $^{* 1}$, Joy Muhia ${ }^{2}$, Lynn Waithera Karanja ${ }^{2}$ \\ ${ }^{1}$ Senior Lecturer, Department of Mental Health, Moi University, Kenya \\ ${ }^{2}$ Bsc. Medical Psychology
}

*Corresponding author: Songole RS, PhD Clinical Psychology, Senior Lecturer in Mental Health, MOI University, Kenya, Tel: +254721208676; E-mail: rogerssongole@gmail.com

Received: October 3, 2018; Accepted: October 18, 2018; Published: October 21, 2018

\begin{abstract}
The study explored the effect of primary care giving (PCG) to mentally ill on family stability (FS) in Mathari hospital, Kenya given the fact that increasing PCG to mentally ill is gradually translating into FS. The study was based on two specific objectives: to examine the effects of Mental illness on the primary care givers and to establish the effects of the forms of PCG. Two hypotheses were tested; $\mathrm{H}_{1}$ : PCG to mentally ill have a significant positive effect on FS; $\mathrm{H}_{2:}$ PCG to the mentally ill has a negative effect on FS. This was a cross section study design. A sample of 260 from 800 care-givers was obtained using Krejce and Morgan table guide. Questionnaires with close ended questions were distributed to care-givers to obtain results that were later screened for accuracy and entered into SPSS (Version 22). A 25-item care-giver self-report used to assess stresslevels of family caregivers for chronically ill older adult patients, with co-efficient Alpha reliability values of .7804, and .98 from two studies by Epstein-Lubow was used to measure FS. Besides, a 14-items care-giver questionnaire adopted from Lifetime resources was adopted to measure care-giving as approved by Benedict \& Dillsboro. The effect of PCG giving to mentally ill on FS was established using paired T-test. Findings showed that; transportation, meal preparations, medication, walking assistance, walking patients and toilet services were given to the mentally ill in Kenya and several factors explained FS: taking care of their mentally ill in Kenya; balance of time, share of resources, discrimination of mentally ill people, stigma as a community and family affair, lack of privacy and too much responsibilities. The study established a positive relationship between PCG to mentally ill and FS in Kenya. Besides, ANOVA results showed a statistically positive significant effect of PH giving on FS in Kenya.
\end{abstract}

Keywords: Primary caregiver (PCG); Mentally ill; Family stability (FS); Effect

\section{Introduction}

Mental health problems are one of the main causes of the burden of disease worldwide [1]. Mental health problems constitute the largest single source of world economic burden, with an estimated global cost of $£ 1.6$ trillion (or US\$2.5 trillion) - greater than cardiovascular disease, chronic respiratory disease, cancer, and diabetes on their own [2]. Mental illness is projected to

Citation: Songole RS, Muhia J, Karanja LW. Effect of Mental Illness on the Primary Care Givers: A Case Study of Mathari Hospital, Kenya. J Anxiety Depress. 2018;1(1):104. 
www.yumedtext.com | October-2018

account for more than half of the projected total economic burden from NCDs over the next two decades and 35\% of the global lost output. Mental illness not only affects the patient but also the family. Due to this, provision of PCG services will lead to significant effects on both the patient and the family. This study explored the effect of PCG to the mentally ill on family stability (FS) in Kenya.

\section{Broad Objective}

To determine the effect of primary care giving to the mentally ill on family stability in Kenya

\section{Specific Objectives}

- Effects of Mental illness on the primary care givers.

- Effects of the forms of PCG.

\section{Significance of the Study}

This study is of significance to reassure families concerned that in spite of the PCG to mentally ill counterpart, stability can still be realized.

\section{Literature Review}

Supporting someone who has experienced psychosis may at times be difficult and stressful. Your relative or friend may appear to be different, either as a direct result of their symptoms or because of the side effects of their medication. Their behavior may be unusual, irritating and hard to cope with, or at times unreasonable and perhaps frightening. As a 'carer' you may need to give emotional support and offer practical help on a day-to-day basis. Your supporting role may consume your time and be emotionally exhausting. When the person you are supporting first becomes unwell, it may feel as if your world has been turned upside down. This later brings in a situation of isolation especially as other family members advocate for relinquishing of responsibility to the mentally ill while few offer continuous support even with minimum help [3].

\section{Methodology}

\subsection{Study design}

This study used causal comparative research design, Historical Research design and Survey research design.

The causal comparative research design which explores cause and affect relationships where causes already exist and cannot be manipulated or modified. It uses what already exists and looks backward to explain why [4]. The choice of causal comparative research design is because the study relates the effects of providing care to the mentally ill to family stability.

The Historical Research design which uses primary sources, secondary sources, and lots of qualitative data sources such as logs, diaries, official records, reports to obtain data [5]. The historical research design has been chosen because this study seeks findings that tested the hypothesis - People who are informal primary caregivers of the mentally ill experience a host of challenges which cause family instability. 
www.yumedtext.com | October-2018

The study also had a Survey research design which attempts to describe and explain conditions of the present by using many subjects and questionnaires to fully describe a phenomenon. According to Zechmeister [6], a survey consists of a predetermined set of questions that is given to a sample. Zechmeister adds that with a representative sample of the larger population of interest (which in this case are the mentally ill and caretakers), one can describe the attitudes of the population from which the sample was drawn.

\subsection{Study area}

The study site was Mathari National Mental Referral and Teaching Hospital- formerly called the Nairobi Lunatic Asylum. Currently, Mathari hospital is referred to as Mathari Psychiatric Hospital, a national referral and teaching psychiatric hospital. It has over 700 beds and admits patients whose behavioral disturbances cannot be managed within the community or their relatives who are too poor to seek treatment in private facilities [7]. Mathari Hospital has over 400 members of staff and a bed capacity of over 700. It has grown to a center for integrated services that include a pediatric and adolescent psychiatric clinic, diabetic clinic, general outpatient services, maternal and child health clinic (MCH), voluntary counseling and testing (VCT), laboratory, pharmacy, dental services, comprehensive care clinic (CCC), Mortuary; radiology, occupational therapy; physiotherapy and TB clinic.

\subsection{Study population}

The study population consisted of 800 respondents.

\subsection{Sampling}

It is very difficult to study all caregivers and families in a defined period of time. Therefore, the researcher used proportions of the categories in study population and data were generalized accordingly.

\subsection{Determination of Sample size}

Sample selection was determined using Krejce and Morgan table guide for determining an appropriate sample of the study population. The study strictly targeted primary care-givers and thus out of 800, a sample of 260 was selected as highlighted in the table.

\subsection{Techniques of sample selection}

\subsubsection{Stratified sampling}

Stratified sampling was used to classify respondents by sex (males and females) because the study population contained both sexes.

\subsubsection{Inclusion criteria:}

- Adults with the age of 18 and above who are primary care givers to the mentally ill.

- Ability to express themselves clearly in English and/or Kiswahili

- Capacity (ability) to give "informed consent"

- Ability to override emotional distress 
www.yumedtext.com | October-2018

\subsubsection{Exclusion Criteria:}

- Those without capacity to give "informed consent"

- Those with mental/emotional "imbalance"

- Those who declined participation

\subsection{Tools of data collection}

The study used a questionnaire consisting of closed ended questions to obtain data from respondents. At the conclusion of the interview, the completed forms were checked for completeness and were then transported and stored in a lockable cabinet in the researcher's identified office. The key to the cabinet was in the custody of the researcher; only the researcher and research assistants had access to personal identities.

\subsection{Measurement of variables}

\subsubsection{Family stability (FS)}

A 25-item care-giver self-report used as means to help physicians assess stress-levels of family caregivers accompanying chronically ill older adult patients to their medical visits. The instrument was used on a sample of 60 care-givers, and the reliability co-efficient Alpha was .7804. This instrument was chosen as relevant for this study because based on available studies conducted using it, the reliability scale is above 0.70 which is recommended for highly reliable results. Secondly, it was a very important instrument because it is specifically dealing with care-givers, and the study too points at care-givers to mentally ill.

\subsubsection{Care-giving}

A care-giver questionnaire adopted from Life-time resources was used to obtain responses for the demographic characteristics of respondents. It consists of the need to investigate age and sex of respondents, relationships that care-givers had with the mentally ill, and the 14 items including transportation, laundry work, house-keeping, shopping, dressing, grooming, bathing, toilet use, meal preparations, finances and taxes, medication and monitoring, check-in monitoring, yard work/repair, and walking assistance.

This approach was used for the study as it explores all basic items involved in responding to the needs of mentally ill. All the fourteen items spelt out describe the tasks that are carried out on regular bases in families taking care of mentally ill people.

\subsubsection{Reliability}

The researcher used Cronbach Alpha $(\alpha)$ coefficients to determine the reliability of the instrument. TABLE 1 below shows results for reliability;

TABLE 1 . Reliability results.

\begin{tabular}{|c|c|c|c|}
\hline Variables & Scale & No. of Items & Cronbach Alpha coefficient \\
\hline Care Giving (CG) & 5-point Likert & 14 & .827 \\
\hline Family stability & 5-point Likert & 25 & .869 \\
\hline
\end{tabular}

(Source: Primary data from care-givers 2015) 
www.yumedtext.com | October-2018

\subsubsection{Data analysis}

Data were entered into computer using SPSS (Version 22) and calculations run automatically using SPSS. Output obtained for each factor was used to generate the summary table. Findings were analyzed descriptively using frequencies and percentages of items respectively.

\subsubsection{Testing Hypotheses}

To test $\mathrm{H}_{1 \text { : }}$ There is a positive statistically significant effect of PCG to mentally ill in Kenya and $\mathrm{H}_{2 \text { : }}$ PCG to mentally ill has a statistically negative significant effect on FS in Kenya, regression analysis was run with significant values established when p-value $<0.05: 0.10$ respectively.

\subsubsection{Procedure}

Before the actual study began, a Pilot study was carried out at Moi Teaching and Referral Hospital at the mental health unit in Eldoret, Kenya.

During the study period, the researcher and his two assistants joined Mathari Hospital staff in the outpatient clinic and mental ward where caregivers were selected according to the inclusion criteria spelt out above. Those meeting the requirements were given explanations for the purpose of the stud and the benefits to them.

Each participant was requested to give consent in an entirely voluntary manner. All relevant information was provided in a language and style that the study participants understood. If they agreed, written or oral consent was obtained. Those who agreed to participate in the study were subjected to screening after recording their patients' bio-demographic data. After the collection of data was completed the information was subjected to statistical analysis as described.

\subsubsection{Ethical considerations}

Permission was sought from the relevant Institutional Research Committees namely; Institutional Research and Ethics Committee (IREC) of Moi University and Moi Referral and Teaching Hospital, and Mathari National Mental Referral and Teaching Hospital.

Informed consent was sought from the family members/caregivers who were not coerced to participate in the study. Participants were allowed to withdraw from the study at any time if they so wished. Confidentiality was assured by excluding one's name and only using assigned numbers.

\subsection{Limitation of the study}

Some of the difficulties which were encountered included the confines within which the study was done. Some primary caregivers were excluded due to ethical considerations as they were not regular/usual caregivers of the patients. The study was limited to 260 informal primary caregivers to the patients. Because of the short period of the study and limited financial resources which could not allow the researcher to carry out the research on a large population. 
www.yumedtext.com | October-2018

\subsection{Data analysis}

\subsubsection{The effect of pcg to mentally ill people on fs in Kenya}

The establishment of the effect of PCG on family stability was done statistically using paired T-Test analysis. Under this analysis of SPSS, results are interpreted to have a positive or negative significance when the p-value (sig.) is equal to (=) of less than $(<) 0.01$ or 0.05 or exclusion at 0.10 . B-values were used to explain percentage effect for each of the items in TABLE 2 on family stability.

TABLE 2. The effect of PCG to mentally ill and FS in Kenya.

\begin{tabular}{|c|c|c|c|c|c|c|c|c|c|}
\hline & \multicolumn{5}{|c|}{ Paired Differences } & \multirow[t]{3}{*}{$\mathbf{t}$} & \multirow[t]{3}{*}{ df } & \multirow{3}{*}{$\begin{array}{l}\text { Sig. } \\
(2- \\
\text { taile } \\
\text { d) }\end{array}$} \\
\hline & & \multirow[t]{2}{*}{ Mean } & \multirow[t]{2}{*}{$\begin{array}{l}\text { Std. } \\
\text { Deviat } \\
\text { ion }\end{array}$} & \multirow[t]{2}{*}{$\begin{array}{l}\text { Std. } \\
\text { Error } \\
\text { Mean }\end{array}$} & \multicolumn{2}{|c|}{$\begin{array}{l}\text { 95\% Confidence } \\
\text { Interval of the } \\
\text { Difference }\end{array}$} & & & \\
\hline & & & & & Lower & Upper & & & \\
\hline Pair 1 & CG1 - FS & .14923 & .85726 & .05317 & .04454 & .25392 & 2.807 & 259 & .005 \\
\hline Pair 2 & $\mathrm{CG} 2-\mathrm{FS}$ & .05308 & .97947 & .06074 & $\begin{array}{c}- \\
.06654\end{array}$ & .17269 & .874 & 259 & .383 \\
\hline Pair 3 & CG3-FS & -.35077 & $\begin{array}{c}1.0505 \\
0\end{array}$ & .06515 & $\begin{array}{c}- \\
.47906 \\
\end{array}$ & $\begin{array}{c}- \\
.22248 \\
\end{array}$ & $\begin{array}{c}- \\
5.384 \\
\end{array}$ & 259 & .000 \\
\hline Pair 4 & CG4 - FS & .10308 & .97348 & .06037 & $\begin{array}{c}- \\
.01581 \\
\end{array}$ & .22196 & 1.707 & 259 & .089 \\
\hline Pair 5 & CG5 - FS & -.19308 & .98105 & .06084 & $\begin{array}{c}- \\
.31288\end{array}$ & $\begin{array}{c}- \\
.07327\end{array}$ & $\begin{array}{c}- \\
3.173 \\
\end{array}$ & 259 & .002 \\
\hline Pair 6 & CG6-FS & .19538 & .92173 & .05716 & .08282 & .30795 & 3.418 & 259 & .001 \\
\hline Pair 7 & CG7 - FS & -.04692 & $\begin{array}{c}1.0105 \\
2 \\
\end{array}$ & .06267 & $\begin{array}{c}- \\
.17033 \\
\end{array}$ & .07648 & -.749 & 259 & .455 \\
\hline Pair 8 & CG8-FS & -.05462 & .75744 & .04697 & $\begin{array}{c}- \\
.14712\end{array}$ & .03789 & $\begin{array}{c}- \\
1.163\end{array}$ & 259 & .246 \\
\hline Pair 9 & CG9-FS & .05692 & .99947 & .06198 & $\begin{array}{c}- \\
.06513\end{array}$ & .17898 & .918 & 259 & .359 \\
\hline $\begin{array}{c}\text { Pair } \\
10\end{array}$ & CG10-FS & .21462 & .91650 & .05684 & .10269 & .32654 & 3.776 & 259 & .000 \\
\hline $\begin{array}{c}\text { Pair } \\
11\end{array}$ & CG11-FS & .26846 & .78162 & .04847 & .17301 & .36391 & 5.538 & 259 & .000 \\
\hline $\begin{array}{c}\text { Pair } \\
12\end{array}$ & CG12-FS & .02615 & .99285 & .06157 & $\begin{array}{c}- \\
.09510\end{array}$ & .14740 & .425 & 259 & .671 \\
\hline $\begin{array}{c}\text { Pair } \\
13\end{array}$ & CG13-FS & .18769 & .82866 & .05139 & .08649 & .28889 & 3.652 & 259 & .000 \\
\hline $\begin{array}{c}\text { Pair } \\
14\end{array}$ & CG14-FS & .11846 & .90421 & .05608 & .00804 & .22889 & 2.112 & 259 & .036 \\
\hline
\end{tabular}

CG=Care-giving; FS= Family Stability: $\mathrm{p}=.001 * * / .005 * * / .10 * *$

TABLE 2 shows findings by item and their effect on family stability. Fourteen pairs were generated and four pairs (CG2-FS, CG7-FS, CG8-FS, CG9-FS, and CG12-FS) were identified not to have a statistical significant effect on family stability. Some items caused negative while others caused positive effects. The mean value was used to interpret findings. Pair 1 represents the effect of providing transport or transporting mentally (CG1) ill people from homes to Mathari hospital on family stability. According to findings, an average of $14.9 \%$ effect of PCG to mentally ill on FS is not by probability but it is as a result of transporting mentally ill people to hospital $(M=.149 ; S D=.857$; $p$-value $=.005)$.

In addition, pair 3 shows that rendering laundry services (CG3-FS) to mentally ill people in Kenya poses a negative effect on FS $(M=-.350 ; S D=1.050 ; p$-value $=.000<.001)$. This is a clear implication that laundry services towards mentally ill 
www.yumedtext.com | October-2018

people contribute to $35 \%$ of instability found in families with mentally ill people. This could be as a result of attitude of other family members towards laundry work as they assume it is just a service that they do not deserve and such time could be used to do other activities. This calls for change of negative perception towards services rendered to mentally ill.

Pair 4 shows that shopping for mentally ill people in families contribute to a positive effect on FS in Kenya; $(M=.103$; $S D=.973$; $p$-value $=.089<.10)$. In other words, shopping (CG4-FS) for mentally ill people could be accompanied by other benefits to other family members. These could include shopping family meals together or universal shopping without discrimination whereby each member of the family benefits thus posing a 10.3\% positive effect on family stability. However, this percentage is relatively small though it is worthy noticing in families.

Pair 5 explains the effect of PCG on FS in relation to provision of dressings (CG5-FS) or helping mentally ill people to dress up their clothes regularly. TABLE 2 shows a negative effect $(M=-.193 ; S D=.981 ; p$-value $=.002<.005)$, implying that a $19.3 \%$ of the negative effects of PCG on FS are as a result of acts related to dressing mentally ill by care-givers. In another interpretation, on average and at $95 \%$ confidence interval, $19.3 \%$ of family instability in Kenya is a result of dressing the mentally ill as part of primary care given to such people. To the researcher's own understanding, this kind of instability could be attributed to various factors most especially lack of empathy by other family members who are expected to be sympathetic to mentally ill people.

In pair 6, the researcher established the extent to which grooming (CG6-FS) contributes to FS among families offering PCG to mentally ill people. According to TABLE 2 above, regular grooming of mentally ill people causes a positive effect on family stability; $(M=.195 ; S D=.921$; $p$-value $=.001)$. This means that an average of $19.5 \%$ effect of PCG on FS is brought about by grooming mentally ill people. Grooming mentally ill combines various issues including using toilets, how to brush teeth, ways of behaving while in public, the required and un-required doings in society, among others. Such lead to general welfare as it maintains positive moral image of the family thus explaining family stability.

Pair 7 (CG7-FS) which stands for bathing the mentally ill was not found to have any significant effect on family stability. Findings are interpreted as being statistically significant if the p-value $\leq .001 * .005 * .10 *$. However, the effect of bathing according to TABLE 2 is $\mathrm{M}=-.0469$ representing a negative effect of $4.6 \%$ which was not considered to be that statistically significant (P-value $=.455>.10$ ). In our tradition and social, bathing is regarded as a requirement for good health and it largely benefits the person bathing. It is normally done at least two times a day and it takes few minutes compared to other activities such as taking patient to hospital and other responsibilities.

In pair 8, the researcher established the effect of toilet use on FS (CG8-FS) and established that it had no statistical significant effect $(M=-.054 ; S D=.757$; $p$-value $=.246>.10)$. Just like bathing, the act of toilet use is taken as a regular obligation which is done for survival and strength to do other pieces of work. Therefore, it is part of life and not counted to have any effect unless if it is ignored.

Pair 9 deals with the effect of PCG to mentally ill in terms of meal preparations. TABLE 2 above illustrates that there is a positive effect caused by preparing meals to mentally ill in as regards FS-CG9-FS; $(M=.056$; $S D=.999 ; p$-value = 
www.yumedtext.com | October-2018

.359>.10). However, this effect was not identified to have a statistical significance as shown by P-values. Considerably, eating is part of life and without food, there is a possibility of losing life or suffering hunger till food is brought. The fact that eating is part of life and in order to eat one has to prepare meals means that no one will take it as serious. No wonder the effect is just $5.6 \%$ because it is taken for formality.

Pair 10 -CG10-FS explains the effect of finances and taxes which go towards meeting needs of mentally ill in a family. A strong statistically significant effect was established with $(M=.214 ; S D=.214 ; p$-value $=.000<.001)$ such that an average of $21.4 \%$ of improvement or enhancement of FS is not by chance but a result of finances and taxes expended on the mentally ill. To the researchers' view, if taxes and finances spent can lead to FS instead of otherwise, then there are higher chances that some financial needs are taken care of by other authorities like well-wishers, donors and government agencies thus leaving no much room for families to spend money in providing required services.

Pair 11-CG11-FS is the effect of medication and monitoring of mentally ill on family stability. A statistically positive significant effect was established $(M=.268 ; S D=.781 ; p$-value $=.000<.001)$ such that an average effect of $26.8 \%$ of PCG to mentally ill is attributed to medication and monitoring of mentally ill people. Medication per se involves expenditures in terms of finances while monitoring consumes times. However, the study has identified that financial expenditure contributes to FS thus hence monitoring medication at home is taken as part of regular family activities and therefore brings no family instabilities.

As already stated above, TABLE 2 shows that the average contribution that checking on mentally ill people causes on FSCG12-FS (Pair 12) is not statistically significant, $(M=.026$; $S D=.992 ; p$-value $=.671>.10)$. This takes us to another pair showing effect of PCG to mentally ill on FS reflected in table 4.5 which is pair 13.

Pair 13-CG13-FS cultivates findings on effect of yard work repair on family stability. TABLE 2 shows that yard work repair has a statistically positive effect on family stability, $(M=.187 ; S D=.828 ; p$-value $=.000<.001)$ such that an average of $18.7 \%$ stability reorganized in families giving primary care to mentally ill people is brought about by yard work. Yard-work is caused by acts of mentally ill people which include throwing dirt in compound, urinating on verandah, defecating in compound/yard especially in absence of guardians or care-givers and related acts. In other words, attention to such failure to maintain hygiene of the yard can easily upset other family members and lead to family instability condemning whoever is concerned.

Finally, TABLE 2 illustrates the effect of walking assistance to FS among families taking care of mentally ill in Kenya. A statistically positive effect was established with $(M=.118 ; S D=.2148$; $p$-value $=.036<.05)$ thus on average, primary caregivers who help mentally ill to walk contributes to $11.8 \%$ of family stability.

Finally, considering that many members of some families got frightened at nursing mentally ill people from same family with others and the fact that there were family instabilities originating from divided minds in favor of taking care of mentally ill, the researcher sought views of care-givers about avoiding the mentally ill relative. In response, $65 \%$ of primary care-givers 
www.yumedtext.com | October-2018

disagreed with the view while $35 \%$ agreed. To those who disagreed, avoiding the mentally ill member could not in any way do away with instabilities in families with mentally ill people.

\subsection{Testing hypotheses}

\subsubsection{Regression analysis}

Regression analysis was run to determine the effect of PCG to mentally ill on FS in Kenya. However, we observed that the background information had a significant interaction effect between the two variables. Two models were run in this respect with the first model establishing the effect of background information on FS and model two catering for effect of PCG.

TABLE 3 has a summary of findings obtained.

TABLE 3. Regression results.

\begin{tabular}{|c|c|c|c|c|c|c|c|c|c|}
\hline \multirow{2}{*}{\multicolumn{2}{|c|}{ Model }} & \multicolumn{2}{|c|}{$\begin{array}{c}\text { Unstandardiz } \\
\text { ed } \\
\text { Coefficients }\end{array}$} & \multirow{2}{*}{$\begin{array}{c}\begin{array}{c}\text { Standardiz } \\
\text { ed } \\
\text { Coefficients }\end{array} \\
\text { Beta }\end{array}$} & \multirow[t]{2}{*}{$\mathbf{F}$} & \multirow[t]{2}{*}{$\mathbf{R}^{2}$} & \multirow[b]{2}{*}{ Ad. $\mathbf{R}$} & \multirow[b]{2}{*}{$\begin{array}{c}\mathbf{R}^{2} \text { chang } \\
\text { e }\end{array}$} & \multirow[b]{2}{*}{$\begin{array}{c}\text { P- } \\
\text { value }\end{array}$} \\
\hline & & $\mathbf{B}$ & S.E & & & & & & \\
\hline \multirow[t]{7}{*}{1} & (Constant) & 2.655 & .114 & & & & & & \\
\hline & $\begin{array}{c}\text { Relationship with } \\
\text { patient }\end{array}$ & .015 & .042 & .050 & & & & & \\
\hline & Marital status & -.031 & .072 & -.064 & & & & & \\
\hline & Gender & .294 & .103 & .484 & 3.443 & .075 & .054 & .075 & .003 \\
\hline & Age of care-takers & -.133 & .036 & -.619 & & & & & \\
\hline & Level of education & .021 & .037 & .077 & & & & & \\
\hline & Employment status & -.047 & .027 & -.118 & & & & & \\
\hline \multirow[t]{8}{*}{2} & (Constant) & 2.248 & .123 & & & & & & \\
\hline & $\begin{array}{c}\text { Relationship with } \\
\text { patient }\end{array}$ & -.004 & .039 & -.012 & & & & & \\
\hline & Marital status & .056 & .068 & .115 & & & & & \\
\hline & Gender & .117 & .100 & .193 & & & & & \\
\hline & Age of care-takers & -.095 & .034 & -.443 & & & & & \\
\hline & Level of education & -.012 & .035 & -.044 & & & & & \\
\hline & Employment status & -.078 & .026 & -.198 & & & & & \\
\hline & PCG & .240 & .037 & .406 & 9.333 & .206 & .184 & .130 & .000 \\
\hline \multicolumn{7}{|c|}{ a. Dependent Variable: Family stability } & & & \\
\hline
\end{tabular}

(Source: Primary data from care-givers 2015)

Two models were run as indicated in TABLE 3 above. However before continuing with analysis, it is important to note that the effect whether positive or negative was significant at $p$-value $\leq .005$. Appendix one show details of this information.

Model 1 catered for the effect of background information on family stability. Analysis of variance (ANOVA) was run and a significant effect was established. The purpose of this establishment was to determine whether or not, the demographic characteristics of; nature of relationship with mentally ill, marital status, gender, age of caretakers, level of education and employment status had a significant effect on Family stability. Findings from ANOVA statistics revealed that $\left(R^{2}=.075\right.$; $F=3.443 ; p$-value $=.003<.005)$. This means that all demographic characteristics have a low statistically significant effect of $7.5 \%$ on FS in Kenya. Details for contribution of each demographic characteristic are as indicated in APPENDIX 1. 
APPENDIX 1: Correllation results.

\begin{tabular}{|c|c|c|c|}
\hline \multicolumn{4}{|c|}{ Descriptive Statistics } \\
\hline & Mean & $\begin{array}{c}\text { Std. } \\
\text { Deviation }\end{array}$ & N \\
\hline $\begin{array}{c}\text { Primary } \\
\text { caregiving }\end{array}$ & 2.7797 & .51351 & 260 \\
\hline Family stability & 2.7277 & .30319 & 260 \\
\hline
\end{tabular}

\begin{tabular}{|c|c|c|c|}
\hline \multicolumn{4}{|c|}{ Correlations } \\
\hline & & $\begin{array}{c}\text { Primary } \\
\text { caregiving }\end{array}$ & $\begin{array}{c}\text { Family } \\
\text { stability }\end{array}$ \\
\hline \multirow{3}{*}{$\begin{array}{c}\text { Primary } \\
\text { caregiving }\end{array}$} & Pearson Correlation & 1 & $.342^{* *}$ \\
\hline & Sig. (2-tailed) & & .000 \\
\hline & $\mathrm{N}$ & 260 & 260 \\
\hline \multirow[t]{3}{*}{ Family stability } & Pearson Correlation & $.342^{* * *}$ & 1 \\
\hline & Sig. (2-tailed) & .000 & \\
\hline & $\mathrm{N}$ & 260 & 260 \\
\hline
\end{tabular}

Model 2 catered for the effect of PCG on family stability. ANOVA results revealed that there is a statistically positive significant effect of PCG on FS in Kenya, $\left(R^{2}=.206 ; F=9.333 ; p\right.$-value $\left.=.000<.005\right)$, implying that a $20.6 \%$ improvement in FS among families taking care of mentally ill people was not by chance but attributed to PCG to mentally ill. This confirms $\mathrm{H}_{1}$ : Primary care giving to mentally ill has a significant positive effect on FS and disapproves $\mathrm{H}_{2 \text { : }}$ Primary care giving to mentally ill has a negative effect on FS in Kenya.

\section{Discussion}

The discussion of findings is in line with the study objectives and in relation to chapter two as well as the theory used to guide the study. The family systems theory was widely used to guide this study because it stressed that individuals cannot be understood in isolation from one another-implying an act of discrimination and an indicator of instability. The theory is based on one of the mental illnesses called schizophrenia. Most important to note however is that it is good for a family to work together towards a common goal and variations in interest brings instability.

\subsection{The effect of PCG to mentally ill and FS}

Using paired T-test statistics, the study established that each of the fourteen factors in TABLE 2 had effects on family stability. However, not all items caused positive significance. Fourteen pairs were generated and four pairs (CG2-FS, CG7FS, CG8-FS, CG9-FS, and CG12-FS) were identified not to have a statistical significant effect on family stability. Some items caused negative while others caused positive effects. Factors which had a positive effect on FS included; transporting mentally ill people to a health facility (Mathari hospital), laundry services, shopping services, dressing services to the mentally ill, grooming the mentally ill and use of toilet facilities among other things. All these factors were computed using the regression function of SPSS and results revealed that all these factors caused an effect of $20.6 \%$ on FS (TABLE 3). This effect however was both positive and negative as elaborated.

Findings by PsychoGuides.com (2014, pp.1-4) revealed that in the short-term, mental health problems can cause people to be alienated from their peers because of perceived unattractive personality traits or behaviors. They can also cause anger, fear, 
www.yumedtext.com | October-2018

sadness and feelings of helplessness if the person does not know or understand what is happening. In the long-term, mental health disorders can drive a person to commit suicide. According to the National Institute for Mental Health, over 90 percent of suicides have depression or another mental disorder as factors.

On the other hand, Bharadwaj \& Gumpta [8] observed that more than 75\% of the patients living in mental hospitals had no contact with any family member. He reported that the burden of care for a chronic illness, the reduced work output of the patient while the stigma attached to mental illness were the main reasons for the "unwanted patient". Gupta et al. report that although $70 \%$ of the patients in the Agra Mental Hospital had one or more family members, more than half of them did not have a single visit from a relative in the previous two years. Surveys of the mental hospitals have also shown that large numbers of long-stay patients have practically no contact with the family.

\section{Conclusion}

Conclusions about the effect of PCG to the mentally ill on FS showed a positive statistically significant effect $\left(R^{2}=.206\right.$; $F=9.333 ; p$-value $=.000<.005)$, as a summation of factors such as transporting mentally ill people to health center $($ Mathari hospital), laundry services, shopping services, dressing services to mentally ill, grooming the mentally ill, use of toilet facilities among others which had positive and negative effects on FS respectively. From the findings obtained, the researcher acknowledged that there were more negative than positive effects of PCG to the mentally ill on family stability.

\section{Recommendations}

The recommendation was there is need to develop resources to work with diverse groups in the population of care givers and assist them with the skills, competencies and psychosocial skills which are essential in caring for the mentally ill in order to enhance family stability.

In this study, many caregivers were unemployed 107(41.2\%) while the age bracket was (20-59yrs) accounting for 248 $(95.3 \%)$ of the respondents. There is need for government subsidies for the caregivers who are unemployed in terms of service delivery for their mentally ill relatives. The age bracket are young people who are supposed to be active and productive members of the society hence need for creation of day-care centres or halfway houses for the mentally ill people to create space for the young caregivers to engage in other productive activities.

\section{REFERENCES}

1. Vos T, Barber RM, Bell B, et al. Global, regional, and national incidence, prevalence, prevalence, and years lived with disability for 301 acute and chronic diseases and injuries in 188 countries, 1990-2013: a systematic analysis for the Global Burden of Disease Study. Lancet. 2015;386(9995):743-800.

2. Insel T. The global cost of mental illness. 2015. http://www.nimh.nih.gov/about/director/2011/the-global-costofmental-illness.shtml

3. Beyondblue. Healthy eating for people with depression, anxiety and related disorders. Hawthorn West Vic: www.beyondblue.org.au

4. Ernest W, Kuhn J. Encyclopedia of Research Design. In: Salkind N, editor. Causal-Comparative Design. United Kingdom: Sage Knowledge; 2010. p 5. 
www.yumedtext.com | October-2018

5. James P. Research design in Occupational education. Oklahoma State University; 1997. p 4.

6. Zechmeister J. Research methods in psychology. New York: McGraw Hill; 2011. p 12-34.

7. Ndetei D, Gatonga P. Improving access to mental health care in Kenya. Ethn Inequal Health Soc Care. 2011;4(3):97-102.

8. Bharadwaj, Gumpta SP. Psycho-social problems of long mental patients. Indian J Psychiatry. 1980;22(3):251-5. 